\title{
Berry phase in strained InSb whiskers
}

\author{
A. Druzhinin ${ }^{1,2}$, I. Ostrovskii ${ }^{1,2}$, Yu. Khoverko ${ }^{1,2}$, N. Liakh-Kaguy ${ }^{1}$, and K. Rogacki ${ }^{2}$ \\ ${ }^{1}$ Lviv Polytechnic National University, 12 S. Bandera Str., Lviv 79013, Ukraine \\ E-mail: druzh@polynet.lviv.ua \\ ${ }^{2}$ Institute of Low Temperature and Structure Research PAS, 95 Gajowicka, Wroclaw, Poland
}

Received May 23, 2018, published online September 26, 2018

\begin{abstract}
Strain influence on the longitudinal magnetoresistance for the $n$-type conductivity InSb whiskers doped by Sn to concentrations $6 \cdot 10^{16}-6 \cdot 10^{17} \mathrm{~cm}^{-3}$ were studied at temperatures from 4.2 to $50 \mathrm{~K}$ and magnetic field up to $10 \mathrm{~T}$. The Shubnikov-de Haas oscillations at low temperatures were revealed in the strained and unstrained samples with all range doping concentration. Some peaks of the longitudinal magnetoresistance split as a doublet in the InSb whiskers with doping concentration in the vicinity to metal-insulator transition. Taking into account peak splitting giant $g$-factor from 30 to 60 was defined for strained and unstrained samples. The magnetoresistance oscillation period of the InSb whiskers doesn't differ under strain for all doping concentration, but Fermi energy increases and electron effective mass $m_{c}$ decreases and consists $0.02 m_{0}$. Berry phase presence was also revealed in strained $n$-InSb whiskers that shows their transition under a strain to topological insulator phase.
\end{abstract}

Keywords: InSb whiskers, longitudinal magnetoresistance oscillations, doping concentration, $g$-factor, Berry phase.

\section{Introduction}

The features of strain-induced effects were studied in the classical semiconductors (silicon, germanium) with doping concentration in the vicinity to the critical concentration of a metal-insulator transition (MIT) at low temperatures [1-4]. At the same time, there are data on the strain-induced MIT, which is associated with radical rearrangement of the conduction band as a result of strain due to the reducing of electron effective mass [5]. The studying of strain-stimulated effects in semiconductors of the A3B5 group is equally important, including further using of such effects in microelectronic devices. Some semiconductor compounds are also very strain-sensitive, for example, $n$-GaSb $(\mathrm{G}[111]=-226)$, $p$-InSb (G [111] = 212) [6].

On the other hand, oscillation phenomena of magnetoresistance as Shubnikov-de Haas $(\mathrm{SdH})$ effect $[7,8]$ were earlier revealed in the InSb compounds at low temperatures down to liquid helium that were induced by the uniaxial strain. These strain-induced effects are a complicated and complex problem. In this case, the InSb whiskers with doping concentration corresponding to the MIT are a good model for studying the influence of strain, due to their morphology, structural perfection and high mechanical strength.

The strain influence on the hole effective mass $m_{c}$ at temperature $4.2 \mathrm{~K}$ was also shown in the doped InSb samples by authors [9]. The effective mass decreases down to
$0.017 m_{e}$ under the largest biaxial compressive strain $1.05 \%$ due to the energy separation between two bands [10].

Moreover, according to recent reports in bismuth-based materials, the emergence of the Berry phase (AaronovBohm oscillations) was observed as a manifestation of topological isolators [11,12]. The Berry phase arises also in strained InSb materials as a result of strong spin-orbit coupling [13]. It can be expected that the use of the straininduced MIT in the InSb whiskers, whose conductivity is due to surface states, will enable the control of the material properties.

The aim of present paper is study magnetoresistance oscillations in $n$-type InSb whiskers with tin doping concentration in the vicinity to metal-insulator transition under influence of compressive strain at low temperatures. The strain was shown to introduce the InSb whisker in topological insulator state, which accompanied with Berry phase appearance.

\section{Experimental procedure}

The $n$-type InSb whiskers with tin doping concentration grown by chemical transport reaction method were the object for the longitudinal magnetoresistance studies. The InSb whiskers with a length of $2-3 \mathrm{~mm}$ and a diameter of $30-40 \mu \mathrm{m}$ were selected for the investigations. Au contacts to $n$-type conductivity InSb whiskers with the diameter $10 \mu \mathrm{m}$ form an eutectic with whiskers under the pulsed 
welding. The contact technique allows to measure whisker longitudinal magnetoresistance using four contacts to the sample.

The InSb whiskers were strained by the mounting them on substrates with a thermal expansion coefficient different from that of InSb material. The similar experimental method with using the thermal strain estimation of the $p$-type conductivity silicon whiskers on different substrates, were shown in work [1]. Copper substrates were used in order to achieve the uniaxial compression strain $\left(\varepsilon=-3.8 \cdot 10^{-3}\right.$ rel. units) at temperature $4.2 \mathrm{~K}$. The thermal strain of the InSb whiskers in the $<111>$ direction was calculated at temperatures $4.2-50 \mathrm{~K}$.

The helium cryostat was used to study the low-temperature magnetoresistance for the $n$-type conductivity InSb whiskers in the range $4.2-50 \mathrm{~K}$. The whisker magnetic properties were studied in magnetic fields $0-10 \mathrm{~T}$ created by Bitter magnet with time scanning of $1.75 \mathrm{~T} / \mathrm{min}$. The stabilized electric current from 1 to $10 \mathrm{~mA}$ depending on InSb whisker resistance was created using the Keithley 224 source. Temperature measuring were carried out with use a $\mathrm{Cu}-\mathrm{CuFe}$ thermocouple.

\section{Experimental results and their discussions}

Three groups of the $n$-type conductivity InSb whiskers with doping concentration (Sn) that correspond to different approximation to critical concentration of the metalinsulator transition were selected for studies of the magnetoresistance:

i) with doping concentration that corresponds to the MIT $\left(2 \cdot 10^{17} \mathrm{~cm}^{-3}\right)$;

ii) with high doping concentration that corresponds to the metal side of the MIT $\left(6 \cdot 10^{17} \mathrm{~cm}^{-3}\right)$;

iii) with doping concentration shifted into the insulator side of the MIT $\left(6 \cdot 10^{16} \mathrm{~cm}^{-3}\right)$.

The strain influence on the longitudinal magnetoresistance in the $n$-type conductivity InSb whiskers at low temperatures down to $4.2 \mathrm{~K}$ were studied in the range of magnetic field $0-10 \mathrm{~T}$. The results of the studies for strained and unstrained samples doped by tin to different concentration in the vicinity to the MIT are shown in Figs. 1-3.

The longitudinal magnetoresistance peaks of the $n$ type InSb whiskers with various doping concentrations $6 \cdot 10^{16}-6 \cdot 10^{17} \mathrm{~cm}^{-3}$ were revealed in the temperature range $4.2-40 \mathrm{~K}$ as in unstrained and also in strained samples (Figs. 1-3). The decreasing of maximum peak amplitudes with temperature increasing was shown in magnetic field range $0-10 \mathrm{~T}$. The values of magnetic field induction at temperature $4.2 \mathrm{~K}$ that corresponds to the longitudinal magnetoresistance peaks for the unstrained and strained InSb whiskers were presented in the Tables 1 and 2 , respectively.

According to well-known developed methodology [14] we constructed Landau fan diagram. The Landau level (LL)
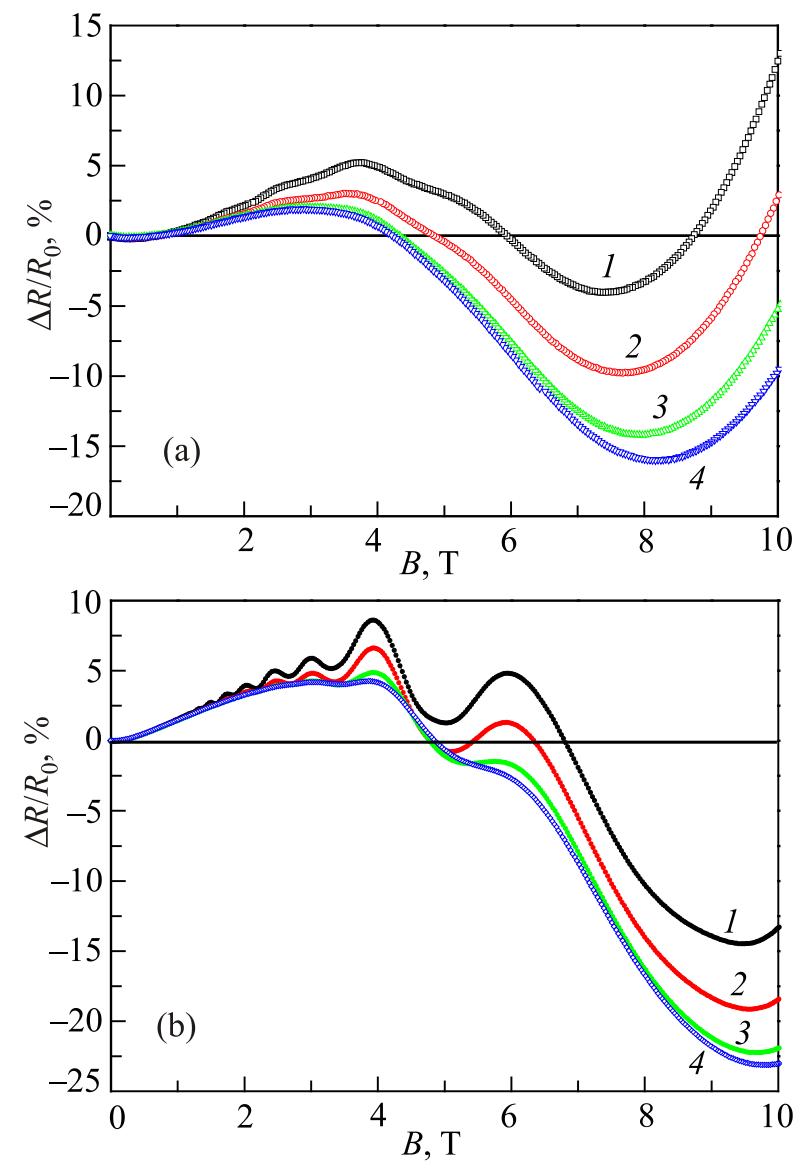

Fig. 1. (Color online) Longitudinal magnetoresistance in the unstrained (a) and strained (b) InSb whiskers tin doped to a concentration $6 \cdot 10^{16} \mathrm{~cm}^{-3}$ at temperatures: $4.2(1), 13(2), 29(3), 40(4) \mathrm{K}$.

index number $N$ to each resistance minimum $(N+1 / 2$ to each resistance maximum) according to experimental data (Figs. 1-3). Landau level index $N$ versus reversal the magnetic field induction $1 / B$ was presented in Fig. 4 (a), (b). As can be seen from the figures, data points fall on the straight lines and the best linear fit was represented by the solid line. An intercept of linear fit with $N$-index axis yielded zero phase $\beta=0$ in the unstrained InSb whiskers with doping concentration $2 \cdot 10^{17} \mathrm{~cm}^{-3}$ that indicates in Schrödinger electron transport responsible for $\mathrm{SdH}$ oscillations (Fig. 4(a)). However, for the strained samples with doping concentrations $2 \cdot 10^{17}$ and $6 \cdot 10^{16} \mathrm{~cm}^{-3}$ the phase $\beta=1 / 2$ was obtained, that is shown in the Figs. 4(b) and 4(c).

Thus, the Berry phase was absent in unstrained $\mathrm{InSb}$ whiskers in whole doping concentration range at low temperatures and shown in the Landau fan diagrams in Fig. 4(a). But their presence was revealed in the strained samples only with doping concentration in the vicinity to the MIT. So, strain influence on the magnetoresistance behavior leads to Berry phase appearance in heavily doped whiskers with strong spin-orbit interaction (Figs. 4(b), (c)).

We show strain influence on the longitudinal magnetoresistance dependences for InSb whiskers with various do- 

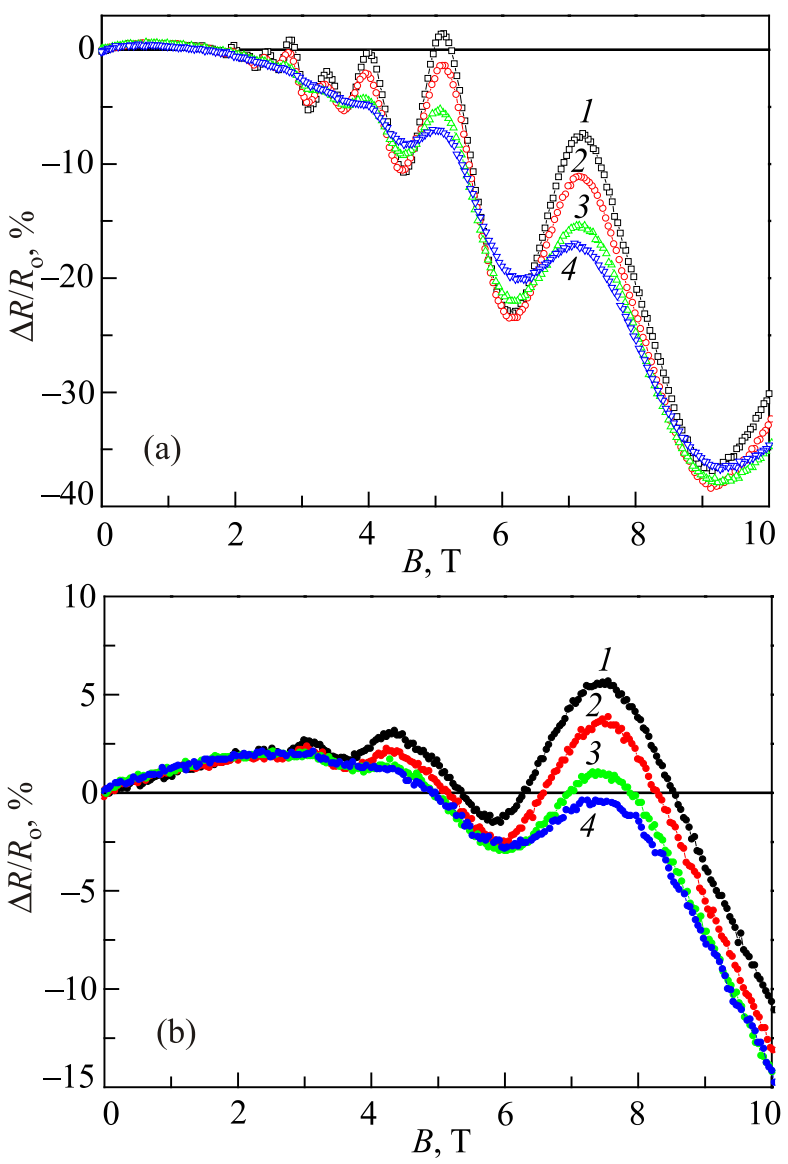

Fig. 2. (Color online) Longitudinal magnetoresistance in the unstrained (a) and strained (b) InSb whiskers tin doped to a concentration $2 \cdot 10^{17} \mathrm{~cm}^{-3}$ at temperatures: 4.2 (1), 13 (2), 29 (3), 40 (4) K.

ping concentrations in all ranges of magnetic fields and temperatures. The peaks corresponding to the transitions between Landau levels with $N=1,2, \ldots$. The number of the longitudinal magnetoresistance peaks decreases from nine peaks in the unstrained samples (Table 1) to six (Table 2) in strained InSb whiskers with doping concentration $2 \cdot 10^{17} \mathrm{~cm}^{-3}$ that corresponds to the MIT (Figs. 2(a),(b)). And for InSb whiskers tin doped to concentration $6 \cdot 10^{17} \mathrm{~cm}^{-3}$ in the vicinity to the MIT from metal side of the transition (Figs. 3(a),(b)) the number of the magnetoresistance peaks doesn't change and consists of 5 in both unstrained and strained samples (see Tables 1, 2). Five peaks with the maxima (Table 1) were revealed on the magnetoresistance dependences at tem-
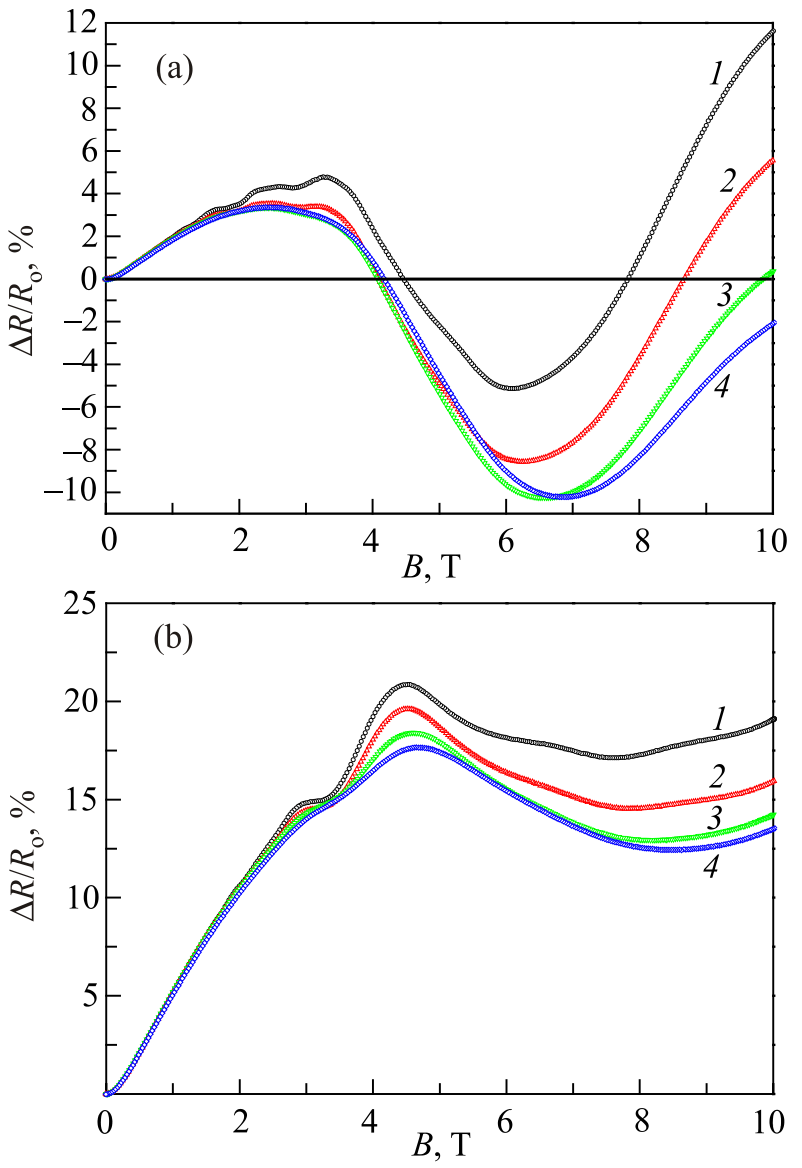

Fig. 3. (Color online) Ongitudinal magnetoresistance in the unstrained (a) and strained (b) InSb whiskers tin doped to a concentration $6 \cdot 10^{17} \mathrm{~cm}^{-3}$ at temperature: $4.2(1), 13(2), 29(3), 40(4) \mathrm{K}$.

perature $4.2 \mathrm{~K}$ for the unstrained InSb whiskers with doping concentration of $6 \cdot 10^{16} \mathrm{~cm}^{-3}$ shifted into the insulator side of the MIT (Fig. 1(a)). But in this case, the number of the peaks increases up to nine (Table 2) for the strained samples (Fig. 1(b)).

The strain influence on the longitudinal magnetoresistance dependences of the InSb whiskers were studied at low-temperature range. So, the influence of strain was manifested due to the doping concentration shift relative to the MIT that corresponds to the change of the magnetoresistance peak number. InSb whiskers with tin concentration $2 \cdot 10^{17} \mathrm{~cm}^{-3}$ was shifted from the MIT that corresponds to the decreasing peak number under the strain (Fig. 2(b)).

Table 1. The magnetic field inductions of the magnetoresistance peaks in the unstrained InSb whiskers with different doping concentration at $4.2 \mathrm{~K}$

\begin{tabular}{|c|c|c|c|c|c|c|c|c|c|c|}
\hline Doping concentration, $\mathrm{cm}^{-3}$ & \multicolumn{10}{|c|}{ The longitudinal magnetoresistance in unstrained samples $B_{\max }, \mathrm{T}$} \\
\hline № & 1 & \multicolumn{2}{|c|}{2} & \multicolumn{2}{|c|}{3} & \multicolumn{2}{|c|}{4} & \multicolumn{2}{|c|}{5} & 6 \\
\hline $6 \cdot 10^{16}$ & & \multicolumn{2}{|c|}{5.4} & & & \multicolumn{2}{|c|}{2.4} & \multicolumn{2}{|c|}{1.8} & 1.4 \\
\hline $2 \cdot 10^{17}$ & 11.4 & 7.2 & 5.1 & 4.0 & 3.4 & 2.85 & 2.5 & 2.2 & 2.0 & \\
\hline $6 \cdot 10^{17}$ & 7.46 & \multicolumn{2}{|c|}{4.3} & \multicolumn{2}{|c|}{3.0} & \multicolumn{2}{|c|}{2.39} & \multicolumn{2}{|c|}{1.96} & \\
\hline
\end{tabular}


Table 2. The magnetic field inductions of the magnetoresistance peaks in the strained InSb whiskers with different doping concentration at $4.2 \mathrm{~K}$

\begin{tabular}{|c|c|c|c|c|c|c|c|c|c|c|}
\hline \hline Doping concentration, $\mathrm{cm}^{-3}$ & \multicolumn{7}{|c|}{ The longitudinal magnetoresistance in unstrained samples $B_{\max }, \mathrm{T}$} \\
\hline \hline № & \multicolumn{2}{|c|}{1} & 2 & 3 & 4 & 5 & 6 & 7 & 8 & 9 \\
\hline $6 \cdot 10^{16}$ & & 5.9 & 4.0 & 3.0 & 2.4 & 2.0 & 1.7 & 1.4 & 1.2 \\
\hline $2 \cdot 10^{17}$ & & 4.1 & 3.2 & 2.35 & 2.0 & 1.5 & 1.0 & & \\
\hline $6 \cdot 10^{17}$ & 8.3 & 6.5 & 4.2 & 2.8 & - & 1.7 & & & & \\
\hline \hline
\end{tabular}

Heavily doped samples with concentration $6 \cdot 10^{17} \mathrm{~cm}^{-3}$ was also shifted from the MIT and magnetoresistance peak num-
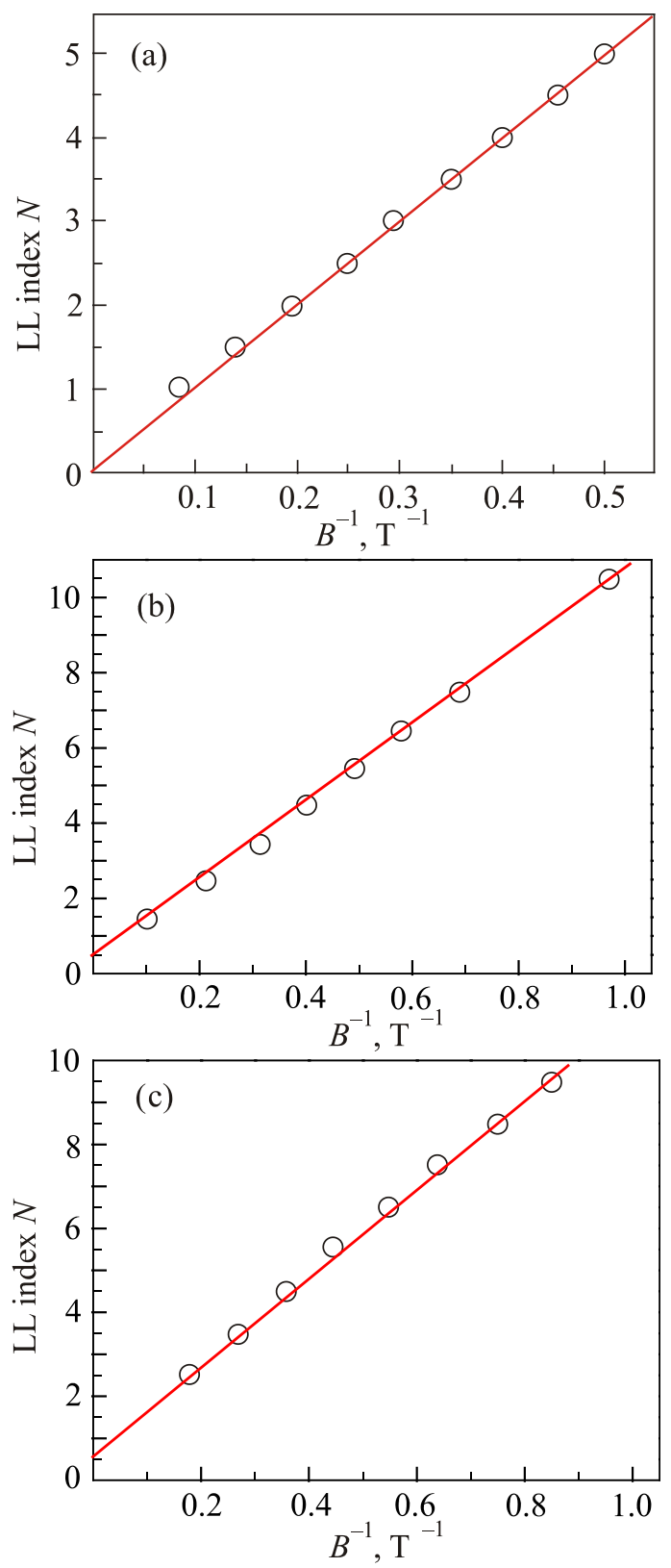

Fig. 4. The Landau level (LL) index $N$ of SdH oscillation versus reverse magnetic field $(1 / B)$ in unstained (a) and strained (b), (c) InSb whiskers with doping concentration $2 \cdot 10^{17}$ and $6 \cdot 10^{16} \mathrm{~cm}^{-3}$, respectively. ber decreased due to the strain (Fig. 3(b)). On the contrary, the lightly doped samples have been shifted from the insulator side of the MIT closer to the transition and the behavior of the longitudinal magnetoresistance was changed by the strain.

The SdH oscillations of the longitudinal magnetoresistance were observed in high quality $n$-type conductivity $\mathrm{InSb}$ whiskers with doping concentration in the range $6 \cdot 10^{16}-6 \cdot 10^{17} \mathrm{~cm}^{-3}$ for both unstrained and strained samples (Figs. 1-3). Every peak of longitudinal magnetoresistance splits as doublet in magnetic field 0-10 $\mathrm{T}$ for the unstrained InSb whiskers with doping concentration $2 \cdot 10^{17} \mathrm{~cm}^{-3}$ that corresponds to the MIT (Fig. 2(a)). Therefore, the $\mathrm{SdH}$ magnetoresistance oscillation splits into two peaks that corresponds to various quantum levels at the inductions of magnetic field: $N=1$ at 7.2 and $5.1 \mathrm{~T} ; N=2$ at 4 and $3.4 \mathrm{~T} ; N=3$ at 2.8 and $2.5 \mathrm{~T} ; N=4$ at 2.2 and $2 \mathrm{~T}$ (Table 1). But for the strained samples with the same doping concentration there had not been any observations of the splitting at all ranges of magnetic fields and temperatures (Fig. 2(b)).

We show quite different situations for the samples that correspond to both the insulator and metal side of the MIT. The strain influence on the longitudinal magnetoresistance of the InSb whiskers with high doping concentration $6 \cdot 10^{17} \mathrm{~cm}^{-3}$ that corresponds to the metal side of the MIT (Fig. 3(b)) leads to splitting a peak $N=1$ at 8.3 and $6.5 \mathrm{~T}$ (Table 2). Nevertheless, the splitting is absent for the unstrained samples in magnetic field $0-10 \mathrm{~T}$ at liquid helium temperature (Fig. 2(b)). The splitting of the magnetoresistance peaks are absent for the lightly doped $n$-type InSb whiskers in both unstrained and strained samples with tin concentration $6 \cdot 10^{16} \mathrm{~cm}^{-3}$ (Fig. 1(a), (b)).

The SdH oscillations are periodic on $1 / H$. The period of the magnetoresistance oscillations $P$ in the opposite magnetic field corresponds to the quadratic dispersion law [15]:

$$
P=\Delta(1 / H)=\frac{\hbar|e|}{E_{F} m_{c} c},
$$

where $e$ is the elementary charge, $E_{F}$ is the Fermi energy, $\hbar$ is the Planck constant; $m_{c}$ is the effective electron mass, $c$ is the light speed.

The longitudinal magnetoresistance period was found due to the Eq. (1). The period of SdH oscillations slightly differs for various doping concentration of the InSb whis- 
kers. The period of the magnetoresistance oscillations is about $0.1 \mathrm{~T}^{-1}$ in the InSb whiskers with doping concentration that correspond to the vicinity to the MIT [16].

$\mathrm{SdH}$ oscillation for the unstrained semimetal-side sample differ from one in the semiconductor-side, that lead to difference in intensity ratio for $\Delta \rho_{3}$ and $\Delta \rho_{2}$, where $\Delta \rho_{2}$ is contribution to the resistance, which corresponds with two terms as the hopping conductance on twice occupied by electrons impurity $\Delta \rho_{2}^{\prime}$ and the electron spin-orbit interaction $\Delta \rho_{2}^{\prime \prime}, \Delta \rho_{3}$ is contribution to the resistance due to the hopping conductance on once occupied by the electron impurity. The scattering by electron spin-orbit interaction is the main mechanism in the semimetals, so $\Delta \rho_{2}^{\prime \prime}$ is the largest and as result the reduction of $\Delta \rho_{3}$-term. So, the splitting was shown in the semimetal side of MIT (Fig. 4). The $\Delta \rho_{3}$-term can increase and may be measurable in the semiconductors. Thus, the peak splitting was observed on the magnetoresistance curves in the vicinity to the MIT that correspond with competition of both $\Delta \rho_{2}$ - and $\Delta \rho_{3}$ terms (see Fig. 2(a)), whereas in addition to MIT, only the $\Delta \rho_{3}$-term dominates, which leads to the absence of the splitting in the magnetoresistance oscillations (Fig. 1(a) and Fig. 3(a)).

Intensity ratio for $\Delta \rho_{2}$ and $\Delta \rho_{3}$ in unstrained sample that corresponds to the MIT would be compared. For the interval of the fields $0-2 \mathrm{~T}$, the intensity ratio $\Delta \rho_{2}>\Delta \rho_{3}$ (Fig. 2(a)), where the amplitude of the oscillations becomes noticeable. Moreover, intensity ratio $\Delta \rho_{2}<\Delta \rho_{3}$ was observed in high magnetic fields 2-10 $\mathrm{T}$ inversion of takes place. We can observe such changes in the intensity ratio due to the MIT inducted by the magnetic field. Such type of the MIT was shown firstly in the work [17] and developed in [18]. $\Delta \rho_{2}-$ term correspond with the strong spin-orbital interaction prevails in weak magnetic fields. A gradual increasing in $\Delta \rho_{3}-$ term corresponds with hopping conductance and occurs in the magnetic field with induction $B>2 \mathrm{~T}$.

Revealed splitting in the magnetoresistance oscillations allow us to define the $g$-factor. Spin splitting of the peaks observed in $\mathrm{SdH}$ oscillations at magnetic field $B_{2}$, when $g^{*} \mu_{B} B$ exceeds the doping level splitting of the Landau $\Gamma=\hbar e B_{1} / m_{c}^{*}$. So, we can write $\Gamma=\hbar e B_{1} / m_{c}=g^{*} \mu_{B} B_{2}$.

Since the Bohr magneton is $\mu_{B}=e \hbar / 2 m_{0}$, thus the expression was obtained

$$
g^{*}=2 \frac{B_{1} m_{0}}{B_{2} m m_{c}^{*}}
$$

The band conduction in the InSb is strongly nonparabolic due to narrow band gap, as result the mass depends on energy [19]:

$$
m^{*}(E)=m_{c}\left(1+\frac{2 E}{E_{g}}\right)
$$

where $E$ is an electron energy, $E_{g}$ is a band gap, and $m_{c b}^{*}$ is an effective mass in the edge of conduction band. According to conduction at Fermi energy, $E=E_{F}$, and using the equation (3) with parameter $m_{c}=0.014 m_{0}$ and $E_{F}==0.11 \mathrm{eV}$ were obtained from the analysis of $\mathrm{SdH}$ oscillations and band gap consists $0.23 \mathrm{eV}$ (in the InSb whiskers at helium temperature [20]) the corresponding values have been calculated for $m^{*}=0.03 m_{0}$ that was used for $g$-factor estimation.

According to above consideration the graduate increasing of the $g$-factor from 46 to 60 for different Landau levels that correspond $N=1$ and $N=4$, respectively, were obtained. Obtained data were in the good agreement with the giant values of the $g$-factor that revealed in the InSb nanowires, but according to the data in work [21] some discrepancy was revealed. Taking into accoount results in the present work, value of the $g$-factor decreases with increasing of the magnetic field induction, while in work [21] $g$-factor value depends on the doping level. The giant amplification of spin splitting near the MIT was also shown in the Si heterostructures [22]. InSb represents as narrow-band gap material. It has the largest electron Lande $g$-factor, which consists 51 for all semiconductors of the A3B5 group [23]. The authors [24] also studied the temperature dependence of the electron Landé $g$-factor in the InSb crystals and showed that the $g$-factor value was 51 at temperature $4.2 \mathrm{~K}$. The resulting large magnitude of the $g$-factors in this work was associated with the emergence of spin-orbit interaction in the whiskers for field of the hopping conductance on twice occupied by the electrons impurities.

The strain influence on the some parameters of the longitudinal magnetoresistance was observed for the $\mathrm{InSb}$ whiskers at low temperatures. So, the calculated value of $g$-factor consists of 50 for the Landau level $N=1$ at magnetic field inductions 8.3 and $6.5 \mathrm{~T}$ in the strained $\mathrm{InSb}$ whiskers with doping concentration $6 \cdot 10^{17} \mathrm{~cm}^{-3}$, which corresponds to the metal side of the MIT (Fig. 3(b)). The strain influence on the effective electron mass $m^{*}$ of the $n$-type conductivity InSb whiskers leads to the decreasing of its value from $0.03 m_{0}$ to $0.02 m_{0}$.

The Berry phase was revealed in the strained $\mathrm{InSb}$ whiskers with doping concentration in the vicinity to the MIT. For both samples with doping concentration removed into the insulator side of the MIT of $6 \cdot 10^{16} \mathrm{~cm}^{-3}$ and that corresponds to MIT of $2 \cdot 10^{17} \mathrm{~cm}^{-3}$ the appearance of the Berry phase was shown under strain influence in the Figs. 4(b),(c). An explanation for their appearance was suggested as the strain influence shift of the samples to the vicinity to the MIT. But the Berry phase was absented in the strained $\mathrm{InSb}$ whiskers with doping concentration of $6 \cdot 10^{17} \mathrm{~cm}^{-3}$ that corresponds to metal side of the MIT because the strain removed their deeper from the transition.

The effect of phase factor in $\mathrm{SdH}$ oscillation could be described by the Lifshitz-Kosevich equation [25]: 


$$
\frac{\Delta \rho}{\rho}=R(B, T) \cos \left[2 \pi\left(\frac{F}{B}+\gamma-\delta\right)\right],
$$

where $R(B, \mathrm{~T})$ contains the hyperbolic and exponential terms describing the temperature and field damping of the $\mathrm{SdH}$ oscillation amplitude, $F$ is the frequency of the $\mathrm{SdH}$ oscillation in $1 / B$ term, $\gamma=1 / 2-(\beta / 2 \pi)$ is the associated Berry's phase (divided by $2 \pi$ ). Berry's phase $\beta=0$ corresponds to the trivial case, which describes unstrained InSb magnetoresistance oscillations. A deviation from this value to $\beta=1 / 2$ indicates in the existence of Dirac particles [26]. The phase shift $\delta$ is determined by the dimensionality of Fermi surface and takes values 0 for $2 \mathrm{D}$ and $1 / 8$ for $3 \mathrm{D}$ cases [27]. The fan diagrams for strained InSb whiskers (Fig. 4(b),(c)) show that $\beta=1 / 2$. Thus, an additional phase shift $\delta$ is equal to zero confirming 2D nature of Dirac electrons in strained InSb whisker and its transition to topological insulator.

The Dingle temperature $T_{D}$ of the $n$-type conductivity $\mathrm{InSb}$ whiskers is defined as a ratio of the $\mathrm{SdH}$ oscillation amplitudes for two successive magnetoresistance maximum at known value of the effective electron mass $m_{c}$ [15]:

$$
\begin{gathered}
\frac{A\left(T, H_{n}\right)}{A\left(T, H_{n+1}\right)}=\left(\frac{H_{n+1}}{H_{n}}\right)^{\frac{1}{2}} \frac{\sinh \left(\frac{2 \pi^{2} k T m_{c} c}{|e| \hbar H_{n+1}}\right)}{\sinh \left(\frac{2 \pi^{2} k T m_{c} c}{|e| \hbar H_{n}}\right)} \times \\
\times \exp \left[\frac{2 \pi^{2} k T_{D} m_{c} c}{|e| \hbar}\left(\frac{1}{H_{n+1}}-\frac{1}{H_{n}}\right)\right] .
\end{gathered}
$$

The Dingle temperatures for both unstrained and strained samples with various doping concentration were determined from the amplitude dependences of the $\mathrm{SdH}$ oscillations (Figs. 1-3) on magnetic field due to the Eq. (5). The highest values of the Dingle temperature reached of up to $12 \mathrm{~K}$ in the unstrained InSb whiskers that could be explained by their heavy doping concentration. The strain influence on this parameter leads to its increasing up to $15 \mathrm{~K}$ in high magnetic fields due to the decreasing of the effective mass under the strain.

\section{Conclusions}

The longitudinal magnetoresistance in strained and unstrained samples of $n$-type conductivity InSb whiskers with doping concentration in the range $6 \cdot 10^{16}-6 \cdot 10^{17} \mathrm{~cm}^{-3}$ in the vicinity to the MIT from metal and insulator side of transition at low temperatures $4.2-40 \mathrm{~K}$ and magnetic fields with the induction up to $10 \mathrm{~T}$ were studied. According to our investigations the longitudinal magnetoresistance peaks were identified as the $\mathrm{SdH}$ oscillations at temperatures $4.2-40 \mathrm{~K}$. Larger number of the magnetoresistance peaks for strained $\mathrm{InSb}$ whiskers than ones for strained samples were visible at helium temperature. Every peak of the longitudinal magnetoresistance for unstrained InSb whiskers with doping concen- tration that corresponds to the MIT of $2 \cdot 10^{17} \mathrm{~cm}^{-3}$ is splitted as doublet in the magnetic field range $2-10 \mathrm{~T}$, but the splitting is absent in the strained samples. For unstrained samples with doping concentration in the vicinity to the MIT from insulator and metal sides of the transition the splitting is also absent in whole magnetic field. However, the strain influence leads to splitting only first peak of the longitudinal magnetoresistance for InSb whiskers with doping concentration that corresponds to the metal side of the MIT of $6 \cdot 10^{17} \mathrm{~cm}^{-3}$.

Main parameters in the strained and unstrained $n$-type conductivity $\mathrm{InSb}$ whiskers were estimated for various level of the doping concentration due to analysis of $\mathrm{SdH}$ magnetoresistance oscillations. The values of the cyclotron effective mass of electrons were changed from $0.03 m_{0}$ to $0.02 m_{0}$ under strain influence. Fermi energy and Dingle temperature also change due to strain influence from 0.12 to $0.14 \mathrm{eV}$ and from 12 to $15 \mathrm{~K}$, respectively. According to splitting the magnetoresistance peaks for InSb whiskers with doping concentration that corresponds to the MIT, giant $g$-factor of 50-60 was obtained, and its values were dependent on the doping level and strain influence.

The Landau fan diagrams confirmed Berry phase presence in the InSb whiskers with doping concentration in the vicinity to the MIT at low temperatures. Berry's phase $\beta=0$ corresponds to the trivial case, which descrybes unstrained $\mathrm{InSb}$ magnetoresistance oscillations. Aplying strain $\left(\varepsilon=-3.8 \cdot 10^{-3}\right.$ rel. units $)$ at temperature $4.2 \mathrm{~K}$ leads to a deviation from this value to $\beta=1 / 2$ indicating in the existence of Dirac particles. The fan diagrams for strained InSb whiskers confirming 2D nature of Dirac electrons in strained InSb whisker and its transition to topological insulator.

1. A. Druzhinin, E. Lavitska, I. Maryamova, M. Oszwaldowski, T. Berus, and H. Kunert, Cryst. Res. Technol. 37, 243 (2002).

2. A.A. Druzhinin, I.I. Maryamova, O.P. Kutrakov, N.S. LiakhKaguy, and T. Palewski, Funct. Mater. 19, 325 (2012).

3. A.A. Druzhinin, I.P. Ostrovskii, Yu.M. Khoverko, N.S. LiakhKaguj, and Iu.R. Kogut, Mater. Sci. Semicond. Processing 14, 18 (2011).

4. E.E. Zubov, Metal Phys. Adv. Technol. 38, 1423 (2016) [in Russian].

5. S.I. Budzulyak, Phys. Chem. Solid State 13, 34 (2012).

6. L. Wang, L. Zhang, L. Yue, D. Liang, X. Chen, Y. Li, P. Lu, J. Shao, and S. Wang, Crystals 7, 63 (2017).

7. A. Druzhinin, I. Ostrovskii, Yu. Khoverko, N. Liakh-Kaguy, I. Khytruk, and K. Rogacki, Mater. Res. Bull. 72, 324 (2015).

8. A. Druzhinin, I. Ostrovskii, Yu. Khoverko, and N. LiakhKaguy, Fiz. Nizk. Temp. 42, 501 (2016) [Low Temp. Phys. 42, 453 (2016)].

9. C.K. Gaspe, M. Edirisooriya, T.D. Mishima, P.A.R. Dilhani Jayathilaka, R.E. Doezema, S.Q. Murphy, M.B. Santos, L.C. Tung, and Y.-J. Wang, J. Vacuum Sci. \& Technol. B 29, 03C110 (2011). 
10. C. Gaspe, M. Edirisooriya, D. Mishima, and Y.J. Wang, Strain, Confinement and Density Dependence of the Effective Mass of Holes in InSb Quantum Wells (2011).

11. H. Murakawa, M.S. Bahramy, M. Tokunaga, Y. Kohama, C. Bell, Y. Kaneko, N. Nagaosa, H.Y. Hwang, and Y. Tokura, Science 342, 1490 (2013).

12. M. Veldhorst, M. Snelder, M. Hoek, C.G. Molenaar, D.P. Leusink, A.A. Golubov, H. Hilgenkamp, and A. Brinkman, Phys. Status Solidi 7, 26 (2013).

13. C. Liu, G.-B. Liu, J.-J. Zhou, and Y. Yao, Comput. Mater. Sci. 112, 428 (2016).

14. D.X. Qu, Y.S. Hor, J. Xiong, R.J. Cava, and N.P. Ong, Science 329, 821 (2010).

15. A.A. Nikolaeva, L.A. Konopko, and D.V. Gutsu, J. Thermoelerctricity 2, 21 (2008).

16. A. Druzhinin, I. Bolshakova, I. Ostrovskii, Yu. Khoverko, and N. Liakh-Kaguy, Mater. Sci. Semicond. Processing 40, 550 (2015).

17. B. Shapiro, Philos Mag. B 50, 241 (1984).

18. S.A. Obukhov, Phys. Status Solidi (b) 242, 1298 (2005).

19. E. Kane, in Narrow Gap Semiconductors Physics and Applications, W. Zawadzki (ed.), Spinger-Verlag, Nimes (1980), Vol. 133, p. 13..

20. D.M. Zengin, J. Phys. D 16, 653 (1983).

21. H.A. Nilsson, P. Caroff, C. Thelander, M. Larsson, J.B. Wagner, L.-E. Wernersson, L. Samuelson, and H.Q. Xu, Nano Letters 9, 3151 (2009).

22. S.V. Kravchenko, A.A. Shashkin, D.A. Bloore, and T.M. Klapwijk, Solid State Commun. 116, 495 (2000).

23. Aruna Ruwan Dedigama, Spin-Orbit Coupling Effects in Indium Antimonide Quantum Well Structures, The University of Oklahoma, Norman, Oklahoma, 3371934 (2009).

24. K.L. Litvinenko, L. Nikzad, C.R. Pidgeon, J. Allam, L.F. Cohen, T. Ashley, M. Emeny, and W. Zawadzki, Phys. Rev. B 77, 033204 (2008).

25. A.F. Young, Y. Zhang, and P. Kim, Physics of Graphene. Nanoscience and Technology, Springer, Cham (2014).

26. G.P. Mikitik and Y.V. Sharlai, Phys. Rev. Lett. 82, 2147 (1999).

27. J. Hu, J.Y. Liu, D. Graf, S.M.A. Radmanesh, D.J. Adams, A. Chuang, Y. Wang, I. Chiorescu, J. Wei, L. Spinu, and Z.Q. Mao, Sci. Rep. 6, 18674 (2016).

\section{Фаза Беррі в деформованих ниткоподібних кристалах $\operatorname{lnSb}$}

\section{А. Дружинін, І. Островський, Ю. Ховерко, N. Liakh-Kaguy, K. Rogacki}

Досліджено вплив деформації на поздовжній магнітоопір ниткоподібних кристалів InSb 3 провідністю $n$-типу, легованих оловом в концентраціях $6 \cdot 10^{16}-6 \cdot 10^{17} \mathrm{~cm}^{-3}$, при температурах від 4,2 до 50 К та магнітних полях до 10 Тл. При низьких температурах осциляції Шубнікова-де Гааза виявлено в деформованих й недеформованих зразках у всьому діапазоні концентрацій допування. Деякі піки поздовжнього магнітоопору розщеплюються в дублети в ниткоподібних кристалах InSb 3 концентрацією допанта, близькою до переходу метал-ізолятор. Беручи до уваги розщеплення піків, для деформованих та недеформованих зразків визначено гігантський $g$-фактор від 30 до 60. Період осциляцій магнітоопору ниткоподібних кристалів $\mathrm{InSb}$ не змінюється в деформованому стані для всіх концентрацій допанта, але енергія Фермі зростає, а ефективна маса електрона $m_{c}$ зменшується і становить $0,02 m_{0}$. Присутність фази Беррі було також виявлено в деформованих ниткоподібних кристалах $n$-InSb, які демонстрували перехід в фазу топологічного ізолятора під дією деформації.

Ключові слова: ниткоподібні кристали InSb, осциляції поздовжнього магнітоопору, концентрація допування, $g$-фактор, фаза Беррі.

\section{Фаза Берри в деформированных нитевидных кристаллах InSb}

\section{А. Дружинин, И. Островский, Ю. Ховерко, N. Liakh-Kaguy, K. Rogacki}

Исследовано влияние деформации на продольное магнитосопротивление нитевидных кристаллов $\mathrm{InSb}$ с проводимостью $n$-типа, легированных оловом в концентрациях $6 \cdot 10^{16}$ $6 \cdot 10^{17} \mathrm{~cm}^{-3}$, при температурах от 4,2 до 50 К и магнитных полях до 10 Тл. При низких температурах осцилляции Шубникова-де Гааза обнаружены в деформированных и недеформированных образцах во всем диапазоне концентраций допирования. Некоторые пики продольного магнитосопротивления расщепляются в дублеты в нитевидных кристаллах $\mathrm{InSb}$ с концентрацией допанта, близкой к переходу металлизолятор. Принимая во внимание расщепление пиков, для деформированных и недеформированных образцов определен гигантский $g$-фактор от 30 до 60 . Период осцилляций магнитосопротивления нитевидных кристаллов InSb не изменяется в деформированном состоянии для всех концентраций допанта, но энергия Ферми возрастает, а эффективная масса электрона $m_{c}$ уменьшается и составляет $0,02 m_{0}$. Присутствие фазы Берри было также обнаружено в деформированных нитевидных кристаллах $n$-InSb, которые демонстрировали переход в фазу топологического изолятора под действием деформации.

Ключевые слова: нитевидные кристаллы InSb, осцилляции продольного магнитосопротивления, концентрация допирования, $g$-фактор, фаза Берри. 